\title{
The p38 mitogen-activated protein kinase is involved in stress- induced phospholipase $D$ activation in vascular smooth muscle cells
}

\author{
Do Sik Min ${ }^{1^{*}}$, Eun-Young Shin ${ }^{2^{*}}$ and \\ Eung-Gook Kim ${ }^{2,3}$ \\ ${ }^{1}$ Department of Physiology, Catholic University Medical College, \\ 505, Banpo-dong, Socho-gu, Seoul 137-701, Korea \\ ${ }^{2}$ Medical Research Institute, Research Institute for Genetic Engi- \\ neering and Department of Biochemistry, College of Medicine, \\ Chungbuk National University, Cheongju 361-763, Korea \\ ${ }^{3}$ Corresponding author: Tel, +82-43-261-2848; \\ Fax, +82-43-274-9710; E-mail, egkim@med.chungbuk.ac.kr \\ *These two authors contributed equally to this work.
}

Accepted 3 January 2002

Abbreviations: p38 MAPK, p38 mitogen-activated protein kinase; ERK, extracellular-signal regulated kinase; PLD, phospholipase D; VSMC, vascular smooth muscle cell; PKC, protein kinase C; MKK3, MAPK kinase 3

\begin{abstract}
Oxidative stress has been implicated in mediation of vascular disorders. Earlier study showed that the exposure of vascular smooth muscle cells (VSMC) to pervanadate (hydrogen peroxide plus orthovanadate) resulted in the accumulation of $\left[{ }^{3} \mathrm{H}\right]$ phosphatidylbutanol. In this study, the effect of pervanadate on the activation of p38 mitogen-activated protein kinase (p38 MAPK) was studied in the VSMC. Pervanadate treatment activated p38 MAPK in a doseand time-dependent manner. Interestingly, specific inhibition of p38 MAPK with SB203580 attenuated pervanadate-induced PLD activation. This correlates with the finding that expression of dominant negative mutants of MKK3/6 inhibited the PLD activation. SB203580 pretreatment also inhibited other cellular stressors (i.e. high osmolarity and UV light)-induced PLD activation. The possible correlationship of p38 MAPK activation with PKC was examined since PKC is reported to be involved in the pervanadateinduced PLD activation. Calphostin C, a PKC inhibitor, suppressed pervanadate-induced p38 MAPK and PLD activation in a dose-dependent manner. These results suggest that PKC-p38 MAPK may represent an upstream pathway of PLD in the signal transduction of cellular stress.
\end{abstract}

Keywords: oxidative stress, pervanadate, p38 mitogenactivated protein kinase, protein kinase $C$, phospholipase D

\section{Introduction}

Pervanadate (mixture of $\mathrm{H}_{2} \mathrm{O}_{2}$ and vanadate) has been reported as a potent insulin-mimetic agent and an inhibitor of protein tyrosine phosphatase in a number of studies (Kadota et al., 1987; Ruff et al., 1997). Treatment with pervanadate thus resulted in the tyrosine phosphorylation of multiple cellular proteins. We have previously reported that one of the cellular targets of pervanadate is phospholipase D (PLD) (Min et al., 1998) and pervanadate-induced PLD activation relates to necrosis of vascular smooth muscle cells (VSMCs) (Shin et al., 2001). PLD catalyzes the hydrolysis of certain phospholipids, such as phosphatidylcholine, to phosphatidic acid (PA) plus the head group. PLD is implicated in a wide range of pathophysiological processes that include inflammation, secretion, proliferation, differentiation, apoptosis (Kang et al., 1997), neuronal and cardiac stimulation, diabetes, and the respiratory burst in neutrophils (Exton, 1994). PLD can be activated in cells by a variety of extracellular stimuli that bind to $G$ protein-coupled receptors or stimulate receptor tyrosine kinases (Exton, 1999). In addition, phorbol esters are potent activators of PLD in a variety of cellular systems, which implicates protein kinase $C$ (PKC) in PLD regulation. Further, oxidative stress such as pervanadate also stimulated PLD activity in Swiss 3T3 fibroblasts and vascular smooth muscle cells (VSMCs) (Min et al., 1998; Shin et al., 2001). However, little is known about the upstream signaling pathway of PLD regulation in response to pervanadate in VSMCs.

Members of the mammalian mitogen-activated protein kinase (MAPK) family include four distinct groups: the extracellular signal-regulated kinases 1 and 2 (ERK1/2), the c-Jun N-terminal kinase (JNK), p38 MAPK, and ERK5. ERK1/2 are generally activated by growth factors, implicating their major role in cell growth and differentiation. In constrast, p38 MAPK and JNK are stimulated in response to many different types of stressors and are involved in cellular stress, inflammation, cell death (Huot et al., 1996) and cytoskeletal rearrangement (Huot et al., 1997). Reactive oxygen species are generated by many stressors and are considered to be common 
mediators in stress-related signaling pathways. For instance, $\mathrm{H}_{2} \mathrm{O}_{2}$ is a potent activator of p38 MAPK (Floyd, 1990; Huot et al., 1997; Ushio-Fukai et al., 1998) and this stimulatory effect is counteracted by antioxidants such as $\mathrm{N}$-acetyl-L-cysteine (Tao et al., 1996). Pervanadate also stimulated p38 MAPK in a dose-dependent fashion in VSMCs (Daum et al., 1998). In respect to signal transduction, MAPK kinase 3 (MKK3) and MKK6 were recently identified as selective activators of p38 MAPK (Enslen et al., 1998).

Both p38 MAPK and PLD are activated in response to pervanadate, a cellular oxidative stress. However, how p38 MAPK activation is associated with PLD activation. In the present study, we show that p38 MAPK is involved in pervanadate-induced PLD activation in VSMCs, and that PKC acts upstream of p38 MAPK.

\section{Materials and Methods}

\section{Materials}

Hydrogen peroxide, sodium orthovanadate, sodium deoxycholate, phenylmethylsulfonyl fluoride (PMSF) and Nonidet P-40 were purchased from Sigma Chemical Co. (St. Louis, MO, USA). SB203580 and calphostin C were purchased from Calbiochem (San Diego, CA, USA). Protein A sepharose, PVDF membrane and ECL western blotting reagents were purchased from Amersham Pharmacia Biotech (Piscatway, NJ, USA). Thin layer chromatography plates and phosphatidylbutanol standard were obtained from Whatman and Avanti Polar Lipids, Inc. (Alabaster, AL, USA). Anti-phospho p38 MAPK (Thr180/Tyr182) antibody and anti-total p38 MAPK antibody were purchased from New England Biolabs (Beverly, MA, USA). Expression vectors containing dominant negative MKK3 [pcDNA3-MKK3 (K/A)] and MKK6 [pcDNA3-MKK6 (K/A)] mutant cDNAs were kindly provided by Dr. R. J. Davis (University of Massachusetts Medical School).

\section{Cell culture}

VSMCs were obtained by collagenase digestion of aortas from seven-week-old Sprague-Dawley rats (ChamleyCampbell et al., 1979). The resulting cell populations were cultured in DMEM containing $8 \mathrm{mM}$ HEPES, 100 units $/ \mathrm{ml}$ penicillin, $100 \mathrm{mg} / \mathrm{ml}$ streptomycin and $10 \%$ fetal bovine serum (Gibco BRL, Paisley, UK). Cultured VSMCs showed the characteristic 'hills and valleys' growth pattern. VSMC purity was confirmed by immunofluorescence using smooth muscle-specific anti-actin antibody. VSMCs at 69 passages were used for experiments.

\section{Transfection}

VSMCs were transfected with an empty vector (pcDNA3) or a plasmid encoding a dominant negative form of
MKK6 [pcDNA3-MKK6 (K/A)] or MKK3 [pcDNA3-MKK3 $(\mathrm{K} / \mathrm{A})$ ], using GeneSHUTTLE-40 (Q. BIOgene, Carlsbad, CA.). Following transfection, cells were incubated for 48 $\mathrm{h}$ at $37^{\circ} \mathrm{C}$ in a $5 \% \mathrm{CO}_{2}$ atmosphere, and then stimulated with pervanadate prior to immunoblotting and measurement of PLD activity. Control experiments to determine transfection efficiency were performed as described previously (Klemke et al., 1998). Briefly, cells were transfected with GFP gene (pEGFP) using GeneSHUTTLE40 and visualized by inverted fluorescence microscopy. We usually obtained $30-35 \%$ transfection efficiency as determined by counting the number of green positive cells relative to the total number of cells per field (200X).

\section{$\left[{ }^{3} \mathrm{H}\right] \mathrm{PtdBut}$ formation in VSMC}

PLD activity was assessed by measuring the formation of $\left[{ }^{3} \mathrm{H}\right]$ phosphatidylbutanol $\left(\left[{ }^{3} \mathrm{H}\right] \mathrm{PtdBut}\right)$. VSMCs were subcultured in 60-mm-diameter tissue culture dishes at $1 \times 10^{6}$ cells/dish. Cells were serum-starved in DMEM for $24 \mathrm{~h}$ before the start of the assay. For the final $20 \mathrm{~h}$ of serum starvation, the cells were labeled with $1 \mu \mathrm{Ci} / \mathrm{ml}$ $\left[9,10-{ }^{3} \mathrm{H}\right]$ myristic acid. Cells were washed three times with $5 \mathrm{ml}$ of phosphate-buffered saline (PBS) and preequilibrated in serum-free DMEM for $1 \mathrm{~h}$. During the final $10 \mathrm{~min}$ of the preincubation, $0.3 \%$ butan-1-ol was included. At the end of the preincubation, cells were treated with pervanadate for the indicated times. Incubations were terminated by removing the medium, followed by washing on ice with $5 \mathrm{ml}$ of ice-cold PBS and an addition of $1.5 \mathrm{ml}$ of ice-cold methanol. Cells were scraped off the plates using a rubber policeman, and the lipids were extracted and separated with methanol/chloroform/0.1 N HCl (1:1:1). The lower phase was dried under $\mathrm{N}_{2}$, resuspended in $30 \mathrm{ml}$ of chloroform/methanol (2:1), and spotted onto a silica gel 60A thin layer chromatography plate (Whatman, Clifton, NJ.). The plates were developed in the upper phase of the solvent system of ethyl acetate/iso-octane/ $\mathrm{H}_{2} \mathrm{O} /$ acetic acid (55:25:50:10) and stained with iodine. A phosphatidylbutanol in the extra lane was used to locate the bands, which were then scraped into a vial containing a scintillation mixture. The radioactivity incorporated into total phospholipids was measured by LSC, and the results are presented as a percentage of the total radioactivity $(\mathrm{cpm})$ incorporated into phosphatidylbutanol.

\section{p38 MAPK activity assay and Western blotting}

Growth-arrested VSMCs were pretreated and lysed in radioimmunoprecipitation assay buffer $(50 \mathrm{mM}$ Tris, $\mathrm{pH}$ 7.5, $1 \%$ Triton $\mathrm{X}-100,1 \%$ deoxycholate, $0.2 \%$ SDS, 150 $\mathrm{mM} \mathrm{NaCl}, 10 \mu \mathrm{g} / \mathrm{ml}$ leupeptin, $10 \mu \mathrm{g} / \mathrm{ml}$ aprotinin, and 1 $\mathrm{mM}$ PMSF) and the lysate was incubated with antiphospho p38 MAPK antibody, and protein A sepharose for $4 \mathrm{~h}$ at $4^{\circ} \mathrm{C}$. The immunoprecipitate was resuspended in $50 \mu \mathrm{l}$ kinase assay buffer $(25 \mathrm{mM}$ Tris, $\mathrm{pH} 7.5,5 \mathrm{mM}$ 
$\beta$-glycerophosphate, $2 \mathrm{mM}$ dithiothreitol, $0.1 \mathrm{mM} \mathrm{Na}_{3} \mathrm{VO}_{4}$, and $10 \mathrm{mM} \mathrm{MgCl}_{2}$ ) containing $0.1 \mathrm{mM} \mathrm{ATP}$ and $2 \mu \mathrm{g}$ GST-ATF2 (a p38 MAPK substrate), and incubated for $15 \mathrm{~min}$ at $30^{\circ} \mathrm{C}$. Reactions were terminated by the addition of 5X SDS-PAGE sample buffer. Proteins were separated on $12 \%$ SDS-polyacrylamide gels, transferred to PVDF membranes and probed with anti-phospho ATF2 antibody (Santa Cruz Biotechnology, Santa Cruz, CA.).

\section{Densitometry}

Quantification of p38 MAPK phosphorylation was performed by analyzing scanned films using Scion Image Beta $3 \mathrm{~b}$ image acquisition and analysis software (Scion Corporation). Levels of phosphorylation are presented as fold increase over the respective controls, based on arbitrary densitometry units.

\section{Results}

\section{Dose- and time-dependent activation of p38 MAPK} by pervanadate

p38 MAPK is regulated by stress-related signals, including the activity of $\mathrm{H}_{2} \mathrm{O}_{2}$ on distinct upstream kinases (Lewis et al., 1998). To determine whether pervanadate stimulates p38 MAPK, cells were exposed to varying

A.

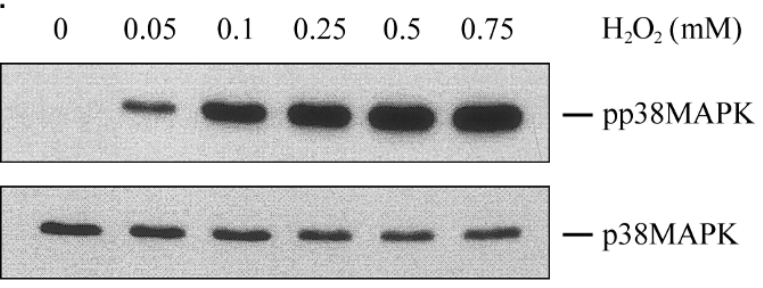

B.

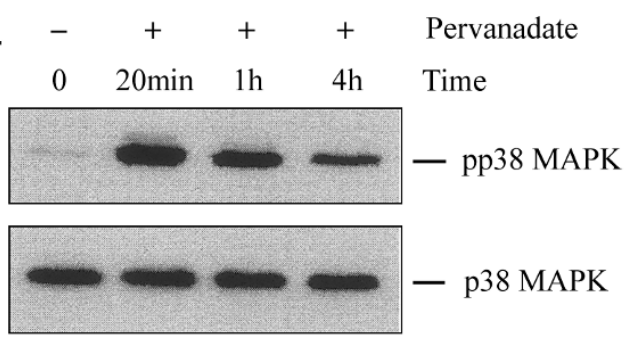

Figure 1. Dose- and time-dependence of pervanadate-stimulated p38 MAPK activation in VSMCs. To measure p38 MAPK activation cells were pretreated with $0.1 \mathrm{mM}$ vanadate, followed by stimulation with the indicated concentrations of $\mathrm{H}_{2} \mathrm{O}_{2}$ for 20 min (A) or with $0.5 \mathrm{mM} \mathrm{H}_{2} \mathrm{O}_{2}$ for the indicated times (B). Lysates were immunoblotted with anti-phospho p38 MAPK antibody, which is specific for the activated, phosphorylated forms (top panel). The blot was stripped and reprobed with anti-total p38 MAPK antibody, which recognizes both phosphorylated and nonphosphorylated forms (bottom panel). Data represent the results of three separate experiments. concentrations of pervanadate, and then p38 MAPK activation was determined by measuring the levels of p38 MAPK phosphorylation, an indication of p38 MAPK activation. Pervanadate stimulated p38 MAPK phosphorylation dose-dependently (Figure $1 \mathrm{~A}$ ), which is consistent with a previous report (Daum et al., 1998). Unexposed VSMCs did not show any significant p38 MAPK phosphorylation. Pervanadate from the mixture of $0.5-1 \mathrm{mM}$ concentrations of $\mathrm{H}_{2} \mathrm{O}_{2}$ plus $0.1 \mathrm{mM}$ vanadate induced maximum p38 MAPK phosphorylation. p38 MAPK phosphorylation by pervanadate peaked at 20 min (Figure 1B). Following this peak, the level of p38 MAPK phosphorylation gradually decreased. These results indicate that pervanadate activates p38 MAPK in a timeand dose-dependent manner in VSMCs.

\section{Role of p38 MAPK in pervanadate-induced PLD activation}

We next examined whether p38 MAPK is involved in pervanadate-induced PLD activation since both PLD and p38 MAPK are activated by pervanadate. SB203580 is widely used as a specific inhibitor of p38 MAPK. Its primary activity is not to block the formation of the active, phosphorylated form of p38 MAPK but rather to inhibit its kinase activity by binding to the ATP acceptor pocket (Young et al., 1997). Thus, the inhibitory effect of SB203580 on pervanadate-induced p38 MAPK activation was evaluated by measuring the enzymatic activity of p38 MAPK in the presence of SB203580. With increasing concentrations of SB203580 pervanadatestimulated p38 MAPK activity gradually decreased (Figure 2A), indicating that SB203580 acts as an inhibitor of p38 MAPK in pervanadate-stimulated VSMCs. As illustrated in Figure 2B, SB203580 pretreatment prevented pervanadate-induced PLD activation in a concentration-dependent manner. SB203580 itself did not influence PLD activity (data not shown). The observation that the inhibition never reached $100 \%$ suggests that there are redundant pathways coupling pervanadate to PLD activation. To rule out the possibility that this phenomenon may be due to nonspecific inhibition of p38 MAPK activity by SB203580, we employed another approach using dominant negative forms of a known upstream activator of p38 MAPK. The plasmid [pcDNA3-MKK6 (K) A)] encoding a dominant negative form of MKK6 (DNMKK6), was introduced into VSMCs, and the cells were then stimulated with pervanadate for $20 \mathrm{~min}$. Phosphorylation of p38 MAPK was greater in the empty vector transfectants than in cells expressing DN-MKK6, indicating that MKK6 acts upstream of p38 MAPK in VSMCs (Figure 2C). Consistent with the lower levels of p38 MAPK phosphorylation, the pervanadate-stimulated PLD activity in pcDNA3-MKK6 (K/A) transfectants dropped to $75 \%$ of the activity seen in the control empty vector transfectants (Figure 2D). SB203580 treatment inhibited 
A.

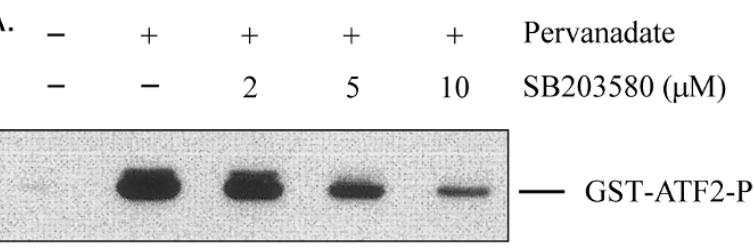

B.

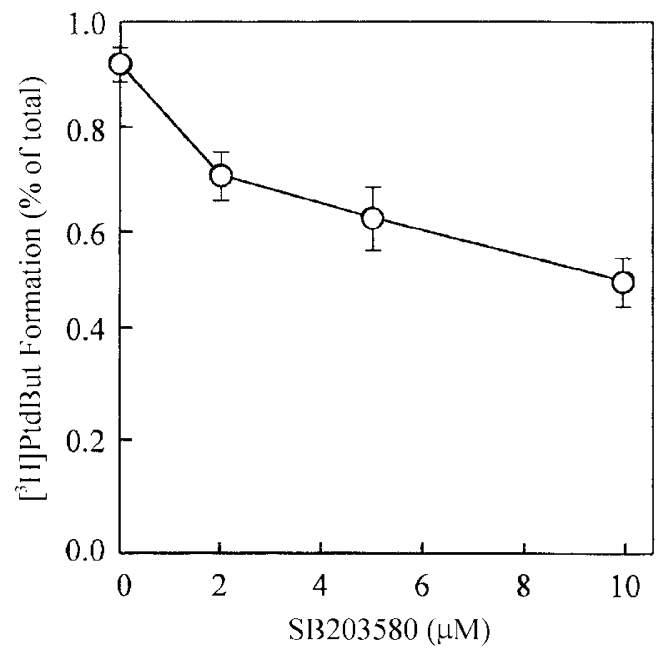

C.
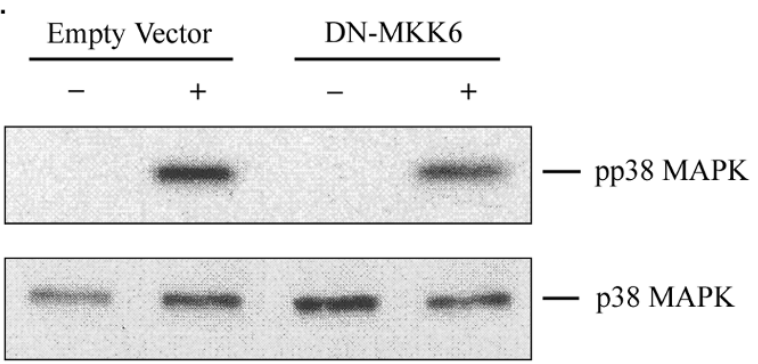

D.

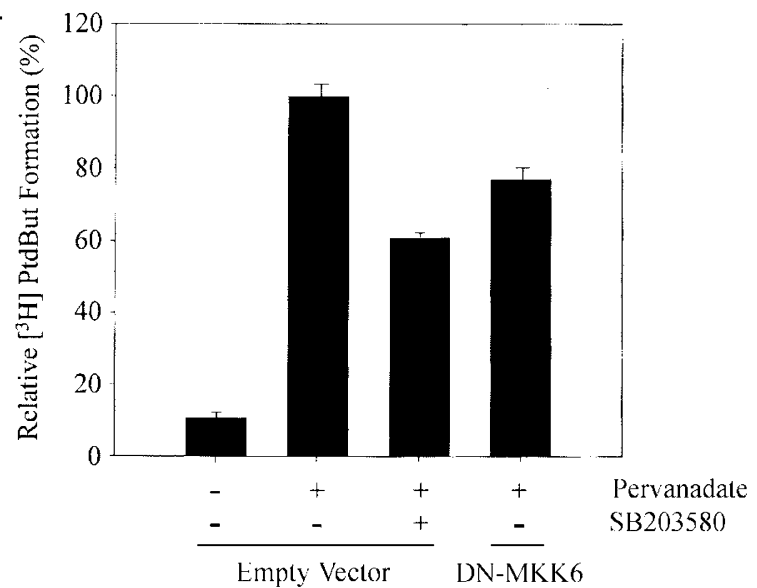

Figure 2. Effect of SB203580 and a dominant negative form of MKK6 on pervanadate-induced p38 MAPK phosphorylation and PLD activation. A, Starved VSMCs were pretreated with $0.1 \mathrm{mM}$ vanadate for $20 \mathrm{~min}$, followed by stimulation with $0.5 \mathrm{mM} \mathrm{H}_{2} \mathrm{O}_{2}$ for 20 min. Lysates were immunoprecipitated with antiphospho p38 MAPK antibody and an in vitro kinase assay was performed using GST-ATF2 as the substrate in either the absence or presence of SB203580. $\mathrm{B},\left[^{3} \mathrm{H}\right]$ Myristate-labeled cells were pretreated with the indicated concentrations of SB203580 for $1 \mathrm{~h}$, followed by stimulation with pervanadate for 20 min. PLD activity was then measured. Data represent three separate experiments conducted in duplicate. C, VSMCs transfected with pcDNA3 (empty vector) or pcDNA3MKK6 (K/A) (DN-MKK6) expressing a dominant negative form of MKK6 were either not treated (-) or stimulated with pervanadate (+) for 20 min. Lysates were immunoblotted with anti-phospho p38 MAPK (top panel), then reprobed with anti-total p38 MAPK (bottom panel). D, Empty vector or DN-MKK6 transfected cells were $\left[{ }^{3} \mathrm{H}\right]$ myristate-labeled and were either not treated $(-)$ or stimulated with pervanadate $(+)$ for 20 min in either the absence or presence of SB203580 (10 $\mu \mathrm{M})$. PLD activity is expressed relative to the pervanadate-stimulated control. Data represent the results of three independent experiments conducted in duplicate.

PLD activity by $40 \%$, which is consistent with the result in Figure 2B. Similar results were obtained with a dominant negative form of MKK3 (data not shown). Taken together, these results strongly suggest that p38 MAPK functions upstream of PLD in pervanadate-stimulated PLD activation.

To further clarify the role of p38 MAPK in the regulation of PLD, we examined whether p38 MAPK mediates phorbol-12-myristate-13-acetate (PMA)-, and other stress (hyperosmolar stress and UV irradiation)induced PLD activation, since these stimuli have been reported to act as strong activators of p38 MAPK (Schultz et al., 1997; Lewis et al., 1998). As shown in Figure $3 \mathrm{~A}$, they stimulated p38 MAPK activation in a dose-dependent manner. Of these stimuli, mannitol exhibited the most potent stimulatory activity (lanes 4 to 6). Incubation of VSMCs with PMA (10 nM for $30 \mathrm{~min}$ ) or mannitol (500 mM for $30 \mathrm{~min}$ ) induced an appreciable PLD activation of $\sim 8$-fold and 7.5 -fold, respectively (Figure $3 B)$. Irradiation of VSMCs with UV light $\left(5 \mathrm{~kJ} / \mathrm{m}^{2}\right)$ caused a modest, (2.5-fold), increase in PLD activity. Pretreatment with SB203580 diminished $\left[{ }^{3} \mathrm{H}\right]$ PtdBut formation in response to PMA, hyperosmolar stress, or UV irradiation in a dose-dependent manner (Figure 3C). Together, these results indicate that p38 MAPK also acts as an upstream activator of PLD in the PMA and other stress signaling pathways.

\section{PKC as an upstream regulator of p38 MAPK in pervanadate-induced PLD activation}

Previous reports, including our observations on Swiss 3T3 cells (Min et al., 1998), suggested that PKC is an important mediator of pervanadate-induced PLD activation. However, whether PKC acts upstream of p38 MAPK in pervanadate-induced PLD activation has not yet been clearly defined. Using calphostin $\mathrm{C}$, a selective inhibitor of PKC, we first examined whether PKC is involved in mediating pervanadate-stimulated $\left[{ }^{3} \mathrm{H}\right] \mathrm{PtdB}$ ut formation in VSMCs. Cells were pretreated with increasing concentrations of calphostin C for 40 min prior to pervana- 
A.

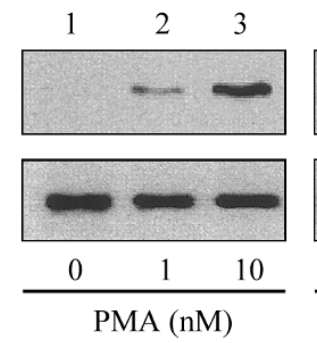

\section{B}

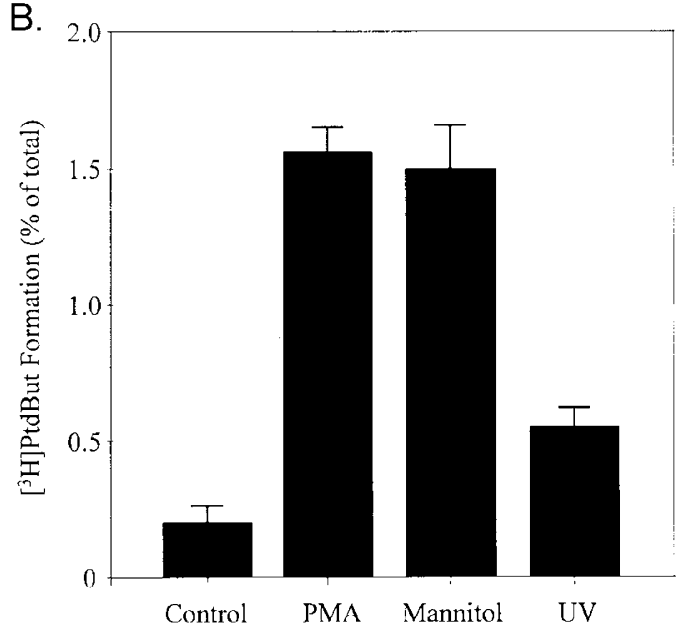

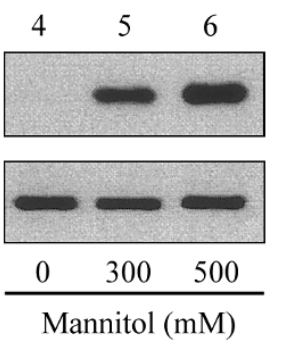

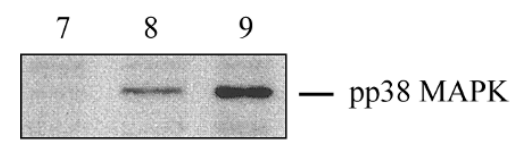

C.

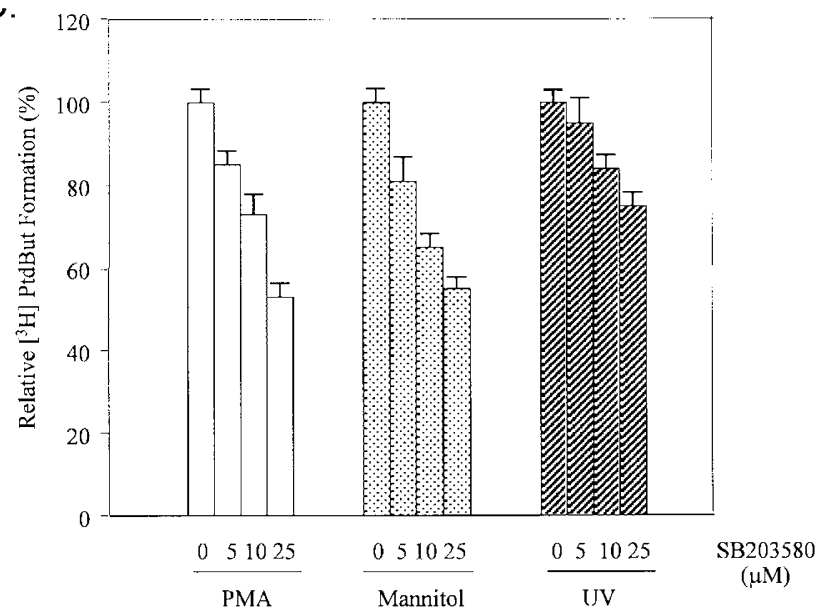

Figure 3. Involvement of p38 MAPK in PMA- and stress-induced PLD activation. A, Starved VSMCs were stimulated with either the indicated concentrations of PMA for 30 min (lanes 1-3) or mannitol for 30 min (lanes 4-6). UV irradiated cells were exposed to UV light (254 nm) at the indicated intensity, followed by a 30 min incubation (lanes 7-9). Lysates were immunoblotted with anti-phospho p38 MAPK antibody (top panel) and the blot was reprobed with anti-total p38 MAPK antibody (bottom panel). B, Cells were stimulated with $10 \mathrm{nM}$ PMA for $30 \mathrm{~min}, 500 \mathrm{mM}$ mannitol for $30 \mathrm{~min}$, or $5 \mathrm{~kJ} / \mathrm{m}^{2}$ UV light. The PLD assay was performed as described in Materials and Methods. Data represent the results of three independent experiments conducted in duplicate. $\mathrm{C}$, $\left.{ }^{3} \mathrm{H}\right] \mathrm{Myristate-}$ labeled cells were pretreated with the indicated concentrations of SB203580 for $1 \mathrm{~h}$ and stimulated with either $10 \mathrm{nM}$ PMA for 30 min, 500 mM mannitol for $30 \mathrm{~min}$, or $5 \mathrm{~kJ} / \mathrm{m}^{2}$ UV light. PLD activity was measured and data represent the results of three separate experiments conducted in duplicate.

date treatment. Stimulation of $\left[{ }^{3} \mathrm{H}\right] \mathrm{PtdBut}$ formation by pervanadate was partially attenuated by calphostin $C$ in a dose-dependent fashion (Figure 4A). Moreover, downregulation of PMA-sensitive PKC isoforms also caused a decrease in $\left[{ }^{3} \mathrm{H}\right] \mathrm{PtdBut}$ formation in response to pervanadate (data not shown). Since these results indicate that pervanadate-induced PLD activation is dependent on PKC in VSMCs, we next determined the effect of PKC inhibition on pervanadate-induced p38 MAPK activation. Calphostin $\mathrm{C}$ pretreatment decreased the phosphorylation level (Figure 4B) and the activity (Figure 4C) of p38 MAPK in a concentration-dependent manner. Calphostin $C$ itself had little effect on activation of p38 MAPK (data not shown). These observations suggest that PKC lies upstream of p38 MAPK in pervanadatestimulated PLD activation. However, mannitol-induced p38 MAPK phosphorylation was not influenced by calphostin C pretreatment, indicating that PKC is not upstream of p38 MAPK in osmotic stress signaling (data not shown). To further determine whether PKC is sufficient for p38 MAPK activation, we investigated the effect on pervanadate-induced PLD activity of a combination of calphostin C and SB203580 (Figure 4D).
Calphostin $C$ itself did not significantly affect the PLD activity in the absence of pervanadate (lane 2). The combination of calphostin C and SB203580 showed an inhibitory effect greater than that observed with either inhibitor alone (lanes 4 to 6 ), but less than the sum of both separate effects. These results suggest that although PKC functions upstream of p38 MAPK in regulation of PLD, additional element(s) other than PKC may signal to p38 MAPK.

\section{Discussion}

Pervanadate stimulated the activation of both p38 MAPK and PLD in VSMCs. PLD activity continued to increase for up to $50 \mathrm{~min}$ after pervanadate exposure (Shin et al., 2001). The increase in PLD activity ( 9fold), however, occurred mostly during the initial 20 min of pervanadate exposure. p38 MAPK activity reached its peak at $20 \mathrm{~min}$. This preceded the time period of maximal PLD activation. Although pervanadate-induced p38 MAPK activity began to decline after $20 \mathrm{~min}$, it was maintained to a significant level for up to $4 \mathrm{~h}$ following 
A.

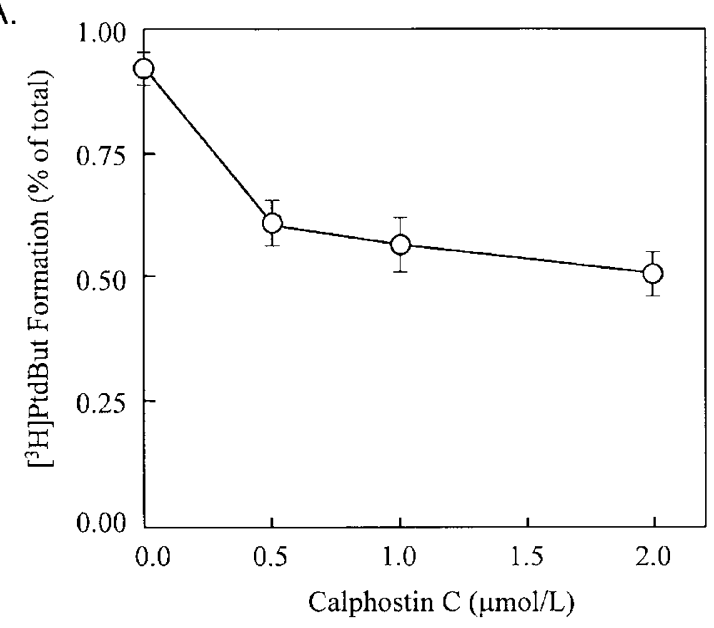

B. -+++ Pervanadate
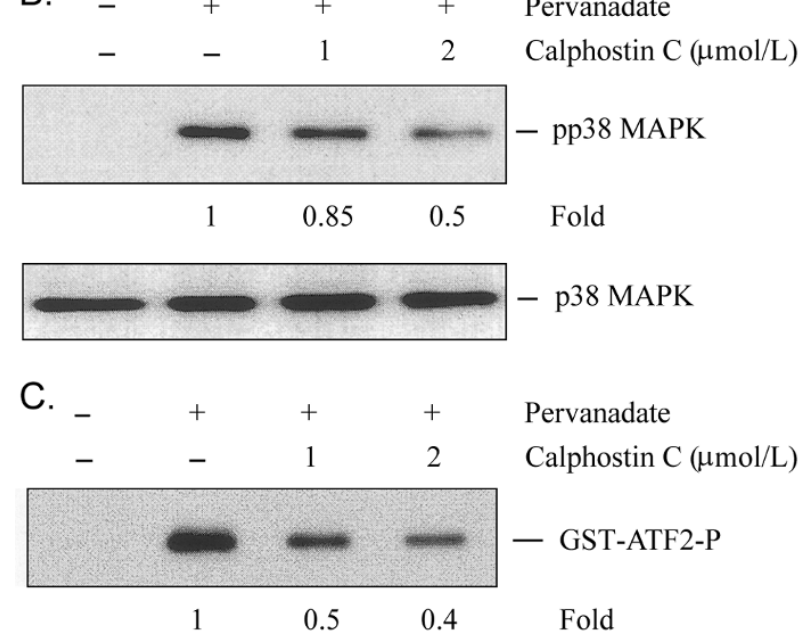

D.

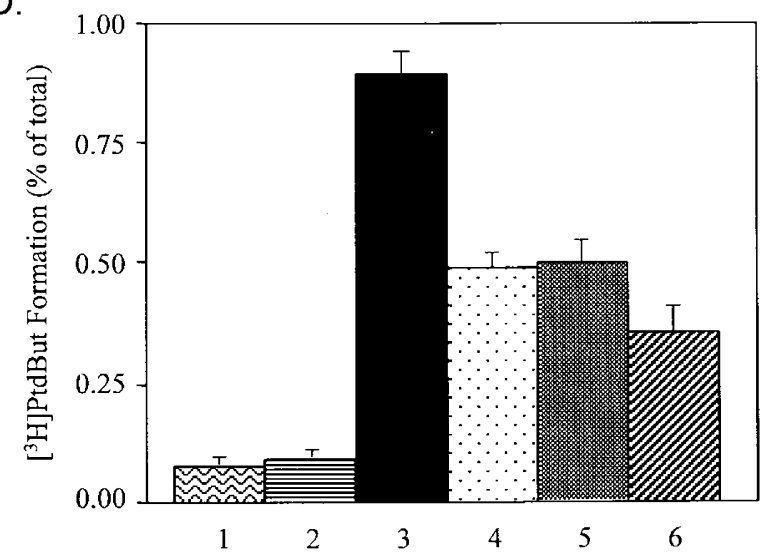

Figure 4. Effect of a PKC inhibitor on pervanadate-induced PLD activation and p38 MAPK phosphorylation. A, [ $\left.{ }^{3} \mathrm{H}\right]$ Myristate-labeled VSMCs were pretreated with the indicated concentrations of calphostin C for $40 \mathrm{~min}$ and stimulated with pervanadate for $20 \mathrm{~min}$, and PLD activity was measured. Data are representative of three separate experiments conducted in duplicate. B, Quiescent cells were pretreated with the indicated concentrations of calphostin C and stimulated with pervanadate as described above, then immunoblotted with anti-phospho p38 MAPK antibody (top panel) and reprobed with anti-total p38 MAPK antibody (bottom panel). C, Cells were processed as described in (B), and p38 MAPK activity was measured by in vitro kinase assays using GST-ATF2 as a substrate. Data are representative of three separate experiments. $\mathrm{D},\left[{ }^{3} \mathrm{H}\right]$ Myristate-labeled cells were untreated (1) or treated with $2 \mu \mathrm{M}$ calphostin $\mathrm{C}$ alone (2) or pervanadate (3). For inhibition of PLD activation cells were pretreated with $2 \mu \mathrm{M}$ calphostin C (4), $10 \mu \mathrm{M}$ SB203580 (5), or $2 \mu \mathrm{M}$ calphostin C/10 $\mu \mathrm{M} \mathrm{SB203580}$ (6) for $40 \mathrm{~min}$, and with pervanadate for $20 \mathrm{~min}$, and the radioactivity incorporated into PtdBut was measured. Data are representative of three separate experiments conducted in duplicate.

pervanadate stimulation. Therefore, at least during the initial 20 min period there is a correlation between the activation of p38 MAPK and PLD. We speculate that the apparent discrepancy between p38 MAPK and PLD activity after 20 min does not exclude their relationship but alludes to the complexity of PLD regulation, in which p38 MAPK participates as a component. It is well established that PLD activity is elaborately controlled by PKC, ADP-ribosylation factors, the Rho family of small $G$ proteins, protein tyrosine kinases and calcium ions (Exton et al., 1999). We propose that p38 MAPK regulates PLD activity based upon the following observations: 1) SB203580 pretreatment resulted in a dosedependent gradual decrease in pervanadate-induced PLD activity (Figure 2B); 2) expression of dominant negative mutants of MKK3/6 caused a significant decrease in the levels of pervanadate-induced PLD activation, although less than those caused by the pharmacological inhibitor SB203580 (Figure 2D); and 3) diverse extracellular stimuli including osmotic stress (mannitol) and UV light, which have been shown to activate p38 MAPK induced PLD activation and inhibition by SB203580 of these stimuli-induced PLD activation was also dose-dependent (Figure 3). This clearly defines a novel pathway involving regulation of PLD by p38 MAPK. While we prepare this manuscript two papers reporting that p38 MAPK regulates PLD were published (Banno et al., 2001; Natarzan et al., 2001). Natarzan and his colleagues (2001) reported that p38 MAPK and PLD are associated in endothelial cells. We also observed the 


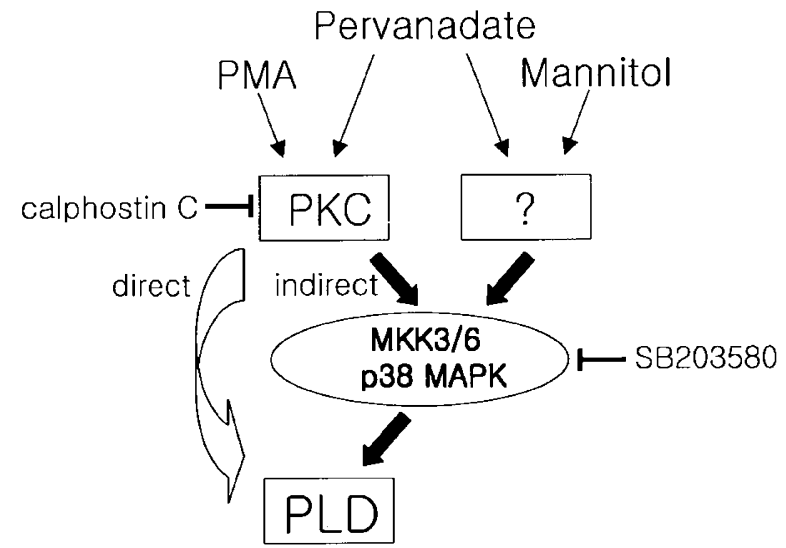

Figure 5. A model for the signaling pathways of PLD activation in VSMCs. Pervanadate enters cells by diffusion and triggers the reactions, which ultimately leads to PLD activation. It is likely that the pervanadate stimulus is delivered through PKC, which subsequently activates PLD. It has not been clear, however, whether p38 MAPK is involved in this process. Our data suggest that PKC could regulate PLD by both p38 MAPK-dependent (indirect) and -independent (direct) mechanisms. In this model we also suggest the role of p38 MAPK for a potential route of PLD activation in delivering the signals from the extracellular stimuli such as mannitol-induced osmotic stress.

presence of p38 MAPK in the PLD immunoprecipitate (data not shown), suggesting that PLD may be similiarly regulated in VSMCs. Finally, we also examined the possible role of ERK1/2 in pervanadate-stimulated PLD activation, since pervanadate is a strong inducer of ERK1/2 and it has been reported that the ERK cascade is implicated in chemoattractant fMet-Leu-Phe (fMLP)and norepinephrine-induced PLD activation (Djerdjouri et al., 1999; Muthalif et al., 2000) as well as in oxidative stress-induced PLD activation in PC12 cells. However, pretreatment with the specific MEK inhibitor PD098059 had no significant effect on PLD activity in VSMCs (data not shown). These results indicate that p38 MAPK specifically activates PLD in pervanadate-stimulated VSMCs.

It is widely accepted that MKK3/6 act as upstream regulators of p38 MAPK (Lewis et al., 1998), although none of the factors which act further upstream in the pervanadate-induced PLD activation cascade have been identified. Pervanadate-induced PLD activation is linked to PKC activation and shows cell-type specificity. In the present study, the selective PKC inhibitor, calphostin C, partially inhibited pervanadate-induced PLD activation in VSMCs (Figure 4). Both the activation of p38 MAPK by pervanadate and PMA (Figure $1 \mathrm{C}$ and $3 \mathrm{~A}$ ), and the inhibition of PLD by SB203580 following exposure to pervanadate and PMA (Figure $2 \mathrm{~B}$ and $3 \mathrm{C}$ ) were dosedependent. This indicates that the PKC-p38 MAPK-PLD pathway exists and is active in VSMCs. There is considerable evidence that in many cell types, the activation of PKC is accompanied by the activation of p38 MAPK. In the signal transduction of ischemic preconditioning, p38 MAPK acts downstream of PKC (Nakano et al., 2000). Additionally, p38 MAPK mediates various cellular activities in a PKC-dependent manner: 1) arsenite-induced activation of AP-1 in JB6 cells (Chen et al., 2000), 2) phorbol ester-induced matrix metalloprotease- 9 secretion in the human squamous cell carcinoma cell line (UMSCC-1) (Simon et al., 1998), 3) the signal from the Gq/ 11-coupled $\mathrm{m} 1$ muscarinic acetycholine receptor in HEK293 cells (Nagao et al., 1998), 4) T cell activation in addition to the maintenance of T cell anergy (DeSilva et al., 1998), 5) phorbol ester- and fMLP-stimulated superoxide anion production in human neutrophils ( $\mathrm{Zu}$ et al., 1998). These results, including our findings with VSMCs suggest that the PKC-p38 MAPK pathway is involved in the regulation of a variety of cellular functions.

Many investigators report that PKC directly activates PLD. Consistent with this notion, PKC- $\alpha$ is constitutively associated with PLD independent of pervanadate stimulation (Min et al., 1998), suggesting that protein-protein interaction might be important for the PKC-mediated PLD activation. It has also been shown that PLD is phosphorylated on the multiple serine/threonine residues by PKC (Kim et al., 2000), suggesting that PKC could directly regulate PLD by phosphorylation. Our data clearly demonstrate that both PKC and p38 MAPK function upstream of PLD, and that PKC functions upstream of p38 MAPK. Thus, it is tempting to speculate that in addition to the direct regulatory role of PKC on PLD activity, there is also an indirect mechanism for PLD regulation, namely via activation of p38 MAPK (Figure 5). If PKC and p38 MAPK might regulate PLD in a linear array of PKC-p38 MAPK-PLD (i.e. PKC is a sufficient upstream regulator of p38 MAPK), inhibitory effect by combination of calphostin C and SB203580 should be equal to that by either inhibitor alone. The combination treatment resulted in a greater inhibition of PLD than either inhibitor alone, although less than the sum of both separate effects (Figure 4D). These results are more consistent with a model, in which PKC could regulate PLD both directly and indirectly (Figure 5). This model also includes the multiple pathways for PLD regulation: for instance, PMA regulates PLD in both p38 MAPKindependent and -dependent pathways; mannitol-induced osmotic stress seems to employ p38 MAPK as a major route for PLD activation, since PKC inhibition by calphostin $C$ only minimally attenuated mannitol-induced p38 MAPK phosphorylation (data not shown); Pervanadate equally utilizes both PKC- and p38 MAPK-dependent pathways, which is supported by the observation that pervanadate-induced PLD activation was inhibited in a similar level by either inhibitor, calphostin C or SB203580 (Figure 4D). Recently, it has been shown that among the PKC isoforms, only PKC- $\alpha$ and PKC- $\varepsilon$ are rapidly translocated into the nucleus upon $\mathrm{H}_{2} \mathrm{O}_{2}(0.1 \mathrm{mM})$ treatment, and therefore activation of these two isoforms may be involved in $\mathrm{H}_{2} \mathrm{O}_{2}$-induced apoptosis of VSMCs 
(Li et al., 1999), although it remains to be determined whether these same two PKC isoforms are the major mediators of necrosis in VSMCs following exposure to pervanadate.

In conclusion, the present study provides evidence that stress-induced PLD activation is mediated in part through PKC-p38 MAPK. Further studies including elucidation of the molecular mechanism whereby p38 MAPK regulates PLD and identification of the specific PKC isoform(s) involved in p38 MAPK activation in VSMCs will provide greater insight into the understanding of stress-induced PLD activation.

\section{Acknowledgement}

This work was supported by the Korean Research Foundation Grant (FP0097).

\section{References}

Chamley-Campbell J, Campbell GR, Ross R. The smooth muscle cell in culture. Physiol Rev 1979;59:1-61

Chen NY, Ma WY, Huang C, Ding M, Dong Z. Activation of PKC is required for arsenite-induced signal transduction. $J$ Environ Pathol Toxicol Oncol 2000;19:297-305

Daum G, Kalmes A, Levkau B, Wang Y, Davies MG, Clowes AW. Pervanadate inhibits mitogen-activated protein kinase kinase-1 in a p38MAPK-dependent manner. FEBS Lett 1998;427:271-74

DeSilva DR, Jones EA, Feeser WS, Manos EJ, Scherle PA. The p38 mitogen-activated protein kinase pathway in activated and anergic Th1 cells. Cell Immunol 1997;180:116-23

Djerdjouri B, Lenoir M, Giroud JP, Perianin A. Contribution of mitogen-activated protein kinase to stimulation of phospholipase $D$ by the chemotactic peptide fMet-Leu-Phe in human neutrophils. Biochem Biophys Res Commun 1999;264:371-75

Enslen H, Raingeaud J, Davis RJ. Selective activation of p38 mitogen-activated protein (MAP) kinase isoforms by the MAP kinase kinases MKK3 and MKK6. J Biol Chem 1998;273: 1741-48

Exton JH. Phosphatidylcholine breakdown and signal transduction. Biochim Biophys Acta 1994;1212:26-42

Exton JH. Regulation of phospholipase D. Biochim Biophys Acta 1999;1439:121-33

Floyd RA. Role of oxygen free radicals in carcinogenesis and brain ischemia. FASEB J 1990;4:2587-97

Huot J, Houle F, Spitz DR, Landry J. HSP27 phosphorylationmediated resistance against actin fragmentation and cell death induced by oxidative stress. Cancer Res 1996;56:27379

Huot J, Houle F, Marceau F, Landr, J. Oxidative stressinduced actin reorganization mediated by the p38 mitogen- activated protein kinase/heat shock protein 27 pathway in vascular endothelial cells. Circ Res 1997;80:383-92

Kadota S, Fantus IG, Deragon G, Guyda HJ, Hersh B, Posner BI. Peroxide(s) of vanadium: a novel and potent insulinmimetic agent which activates the insulin receptor kinase. Biochem Biophys Res Commun 1987;147:259-66

Kang JH, Shin I, Han JS. Changes of phospholipase D activity in TNF-alpha and anti Fas/Apo1 monoclonal antibody induced apoptosis in HL-60 and A20 cells. Exp Mol Med 1998;30:2127

Kim Y, Han JM, Han BR, Lee KA, Kim JH, Lee BD, Jang IH, Suh PG, Ryu SH. Phospholipase D1 is phosphorylated and activated by protein kinase $\mathrm{C}$ in caveolin-enriched microdomains within the plasma membrane. J Biol Chem 2000; 275:13621-27

Klemke RL, Leng J, Molander R, Brooks PC, Vuori K, Cheresh DA. CAS/Crk coupling serves as a "molecular switch" for induction of cell migration. J Cell Biol 1998;140: 961-72

Lewis TS, Shapiro PS, Ahn NG. Signal transduction through MAP kinase cascades. Adv Cancer Res 1998;74:49-39

Li PF, Maasch C, Haller $H$, Dietz $R$, von Harsdorf $R$. Requirement for protein kinase $C$ in reactive oxygen speciesinduced apoptosis of vascular smooth muscle cells. Circulation 1999;100:967-73

Min DS, Kim EG, Exton JH. Involvement of tyrosine phosphorylation and protein kinase $\mathrm{C}$ in the activation of phospholipase D by $\mathrm{H}_{2} \mathrm{O}_{2}$ in Swiss 3T3 fibroblasts. J Biol Chem 1998;273: 29986-94

Muthalif MM, Parmentier JH, Benter IF, Karzoun N, Ahmed A, Khandekar Z, Adl MZ, Bourgoin S, Malik KU. Ras/mitogenactivated protein kinase mediates norepinephrine-induced phospholipase $\mathrm{D}$ activation in rabbit aortic smooth muscle cells by a phosphorylation-dependent mechanism. J Pharmacol Exp Ther 2000;293:268-74

Nagao M, Yamauchi J, Kaziro Y, Itoh $\mathrm{H}$. Involvement of protein kinase $C$ and Src family tyrosine kinase in Galphaq/11induced activation of c-Jun N-terminal kinase and p38 mitogen-activated protein kinase. J Biol Chem 1998;273:22892-98

Nakano A, Cohen MV, Downey JM. Ischemic preconditioning: from basic mechanisms to clinical applications. Pharmacol Ther 2000;86:263-75

Schultz H, Engel K, Gaestel M. PMA-induced activation of the p42/44ERK- and p38RK-MAP kinase cascades in HL-60 cells is PKC dependent but not essential for differentiation to the macrophage-like phenotype. J Cell Physiol 1997;173:310-18

Ruff SJ, Chen K, Cohen S. Peroxovanadate induces tyrosine phosphorylation of multiple signaling proteins in mouse liver and kidney. J Biol Chem 1997;272:1263-67

Shin EY, Min DS, Shin JC, Shin KS, Hyun MS, Ha KS, Kim HS, Ahn HY, Kim EG. Involvement of phospholipase D in oxidative stress-induced necrosis of vascular smooth muscle cells. FEBS Lett 2001;508:277-81

Simon C, Goepfert H, Boyd D. Inhibition of the p38 mitogen- 
activated protein kinase by SB 203580 blocks PMA-induced $\mathrm{Mr}$ 92,000 type IV collagenase secretion and in vitro invasion. Cancer Res 1998;58:1135-39

Tao J, Sanghera JS, Pelech SL, Wong G, Levy JG. Stimulation of stress-activated protein kinase and p38 HOG1 kinase in murine keratinocytes following photodynamic therapy with benzoporphyrin derivative. J Biol Chem 1996;271:27107-15

Ushio-Fukai M, Alexander RW, Akers M, Griendling KK. p38 Mitogen-activated protein kinase is a critical component of the redox-sensitive signaling pathways activated by angiotensin II. Role in vascular smooth muscle cell hypertrophy. J Biol Chem
1998;273:15022-29

Young PR, McLaughlin MM, Kumar S, Kassis S, Doyle ML, McNulty D, Gallagher TF, Fisher S, McDonnell PC, Carr SA, Huddleston MJ, Seibel G, Porter TG, Livi GP, Adams JL, Lee JC. Pyridinyl imidazole inhibitors of p38 mitogen-activated protein kinase bind in the ATP site. J Biol Chem 1997;272: 12116-21

Zu YL, Ai Y, Gilchrist A., Labadia ME, Sha'afi RI, Huang CK. Activation of MAP kinase-activated protein kinase 2 in human neutrophils after phorbol ester or fMLP peptide stimulation. Blood 1996;87:5287-96 